\title{
ANALISIS FAKTOR YANG MEMPENGARUHI KUALITAS TIFUR PENDERITA HIPERTENSI
}

\author{
NurMelizza*, YoyokBektiPrasetyo, NurLailatulMasruroh, AnggrainiDwiKurnia \\ ${ }^{1}$ DepartemenKomunitas, FakultasIlmu Kesehatan, Universitas Muhammadiyah Malang \\ E-mail:melizza@umm.ac.id
}

\begin{abstract}
The incidence of hypertension is still very high in various ages and genders. Hypertension itself is caused by several factors, namely stress and consumption of foods that contain excessive salt. While the risk factors include family history, lifestyle, poor diet, smoking, racial sex, and age. Another factor that is often overlooked is sleep patterns. This study aims to determine what factors can affect the quality of sleep in patients with hypertension. The research design used a cross-sectional study approach with a total sample of 57 hypertension patients under the work area of PuskesmasCiptomulyo Malang City and the sampling technique used was accidental sampling. The questionnaires used included the Pittsburgh Sleep Quality Index (PSQI) and DASS 42. The results showed that the demographic data of respondents with the category of the late elderly 56-65 years were 22 respondents (38.6\%), female gender was 35 respondents (61, 4\%), SD education level was 32 respondents (40.4\%), and worked as many as 35 respondents $(61.4 \%)$. The results of the correlation test showed that the characteristics of respondents that affected the quality of sleep in patients with hypertension were age ( $p$ $=0.014)$ and gender $(p=0.005)$. Meanwhile, the factors that affect the sleep quality of hypertensive patients are psychosocial stress with a $p$-value $=0.001$. So it can be concluded that the factors that affect the quality of sleep in patients with hypertension are age, gender, and psychosocial stress.
\end{abstract}

Keyword : hypertension, sleep quality, PSQI influencing factors

\begin{abstract}
ABSTRAK
Angkakejadianpenyakithipertensimasihsangattinggipadaberbagaikalanganusiadanjeniskelamin.

Hipertensisendiridisebabkanolehbebrapafaktoryaitu stress dankonsumsimakanan yang memilikikandungangaramberlebihan. Sedangfaktorresikonyaantara lain riwayatkeluarga, gayahidup, polamakan yang buruk, merokok, jeniskelaminrasdan juga usia. Adapunfaktor lain yang seringdiabaikanadalahpolatidur. Penelitianinibertujuanuntukmengetahuifaktorapasaja yang dapatmempengaruhikualitastidurpenderitahipertensi. Design penelitian menggunakanpendekatan cross sectional studydenganjumlahsampelsebanyak 57 orang pasienhipertensi di bawahwilayahkerjaPuskesmasCiptomulyo Kota Malang dantehnik sampling yang digunakanadalah accidental sampling. Kuesioner yang digunakanantara lain Pittsburgh Sleep Quality Index (PSQI) dan DASS 42. Hasil penelitian menunjkkan bahwa data demografi responden dengan kategori usia lansia akhir 56-65 tahun sebanyak 22 responden $(38,6 \%)$, jenis kelamin perempuan sebanyak 35 responden $(61,4 \%)$, tingkat pendidikan SD sebanyak 32 responden $(40,4 \%)$, dan bekerja sebanyak 35 responden $(61,4 \%)$. Hasil uji kolerasi menunjukkan karakteristik responden yang mempengaruhi kualitas tidur penderita hipertensi adalah usia $(\mathrm{p}=$ $0,014)$ dan jenis kelamin $(\mathrm{p}=0,005)$. Sedangkan faktor yang mempengaruhi kualitas tidur penderita hipertensi adalah stress psikososial dengan nilai $\mathrm{p}$ value $=0,001$. Sehingga dapat disimpulkan bahwa faktor yang mempengaruhi kualitas tidur penderita hipertensi adalah usia, jenis kelamin dan stress psikososial.
\end{abstract}

Kata kunci : hipertensi, kualitas tidur, PSQI, faktor yang mempengaruhi

\section{PENDAHULUAN}

Sample Registration System (SRS) Indonesia pada tahun 2014, menyatakan bahwa hipertensi yang disertai komplikasi adalah penyebab dari kematian nomer lima tertinggi pada berbagai usia. Menurut Riskesdas pada tahun 2018 menyatakan prevalensi kejadian hipertensi pada penduduk yang berusia 18 tahun sebesar $34,1 \%$, pada penduduk yang berusia 31-44 tahun sebesar $31,6 \%$, pada penduduk yang berusia 45-54 tahun sebesar $45,3 \%$ sedangkan pada penduduk yang berusia 55-64 tahun sebesar 55,2\%. Angka kejadian pada Provinsi Jawa Timur presentasenya mencapai $20,43 \%$ atau berkisar sebanyak 1.828 .669 juta penduduk, dengan pembagian laki-laki sekitar 825.412 penduduk dan perempuan sebesar 1.003.257 penduduk (5).

Hipertensi juga dapatdisebabkanoleh stress sertakonsumsimakanan yang memilikikandungangaramberlebihan.

Faktorresikopadakejadianhipertensimeliputiriwayat keluarga, gayahidup, polamakan yang buruk, 
merokok, jeniskelaminrasdan juga usia (7). Adapunfaktor lain yang tidakkonvensionaldan juga seringdiabaikanolehbeberapa orang adalahpolatidur (8).

HasilpenelitianSuwartika\&Cahyati (2015) (10), menunjukkanbahwakebiasaanminum kopi $(\mathrm{p}=0,001), \quad$ kebiasaanmerokok $\quad(\mathrm{p}=0,004)$ dantingkatkeparahanpenyakit $\quad(p=0,028)$ mempunyaipengaruh yang signifikanterhadapkualitastidurpasiengagaljantung. Penelitian lain menyatakanbahwaderajathipertensidanstrespsikosos ialmempengaruhikualitastidurseseorang,

dimanapasienhipertensiringanmempunyaikualitastid urbaik,

pasienhipertensisedangdanberatmempunyaikualitast idurburuk.

Pasienhipertensiringanmemilikistresringan, pasienhipertensisedangmemilikistressedang, pasienhipertensiberatmemilikistresberat.

Disimpulkanbahwasemakinberathipertensipasien, semakinrendahkualitastidurnyadansemakintinggitin gkatstresnya.Temuaninimenunjukkanbahwakualitas tidurdapatmempengaruhitekanandarahpadapenderit ahipertensidanbanyakfaktor yang mempengaruhikualitastidurpenderitahipertensidiant aranyaderajathipertensi, strespsikososial, kebiasanminum kopi, kebiasaanmerokok, dantingkatkekambuhanhipertensi.

Berdasarkanpenjelasantersebutdiatas,

makapenelitianinibertujuanuntukmengetahuifaktora pasaja yang dapatmempengaruhikualitastidurpenderitahipertensi (3).

\section{METODE PENELITIAN}

\section{Design}

menggunakanpendekatan study.Sampeldantempatpenelitian digunakanadalahPasienhipertensi bawahwilayahkerjaPuskesmasCiptomulyo penelitian sectional yang di Malang. Tehnik sampling yang digunakanadalah accidental sampling selama 1 bulanpadaagustus 2020dengankriteriainklusi: pasienhipertensi yang bersediamenjadiresponden,

sedadkankriteriaekslusinyaadalahpasienhipertenside nganpenyakitpenyerta. Respondensejumlah 57 orang.

KuesionerkualitastidurmenggunakanPittsburgh Sleep Quality Index (PSQI), penilaian tingkat stres psikososial menggunakan item stres dari kuesioner DASS 42 dan klasifikasi derajat hipertensi responden menurut World Health Organization (WHO) (11).

\section{HASIL DAN PEMBAHASAN}

\section{Karakteristik Data Demografi Responden}

Tabel

1.

Distribusifrekuensidanhubungankarakteristik data demografirespondendengankualitastidurpenderitahi pertensi

\begin{tabular}{lllll}
\hline \multirow{2}{*}{ No. } & Karakteristik & \multicolumn{3}{c}{ Kualitastidur } \\
\cline { 3 - 4 } & $\begin{array}{l}\text { Baik } \\
(\mathbf{f} / \%)\end{array}$ & $\begin{array}{l}\text { Buruk } \\
(\mathbf{f} / \%)\end{array}$ & $\begin{array}{l}\mathbf{P} \\
\text { value }\end{array}$ \\
\hline 1. & $\begin{array}{l}\text { Usia } \\
\text { Remajaakhir } \\
(17-25)\end{array}$ & $0(0,0)$ & $2(3,5)$ & \\
$\begin{array}{l}\text { Dewasaawal } \\
(26-35)\end{array}$ & $0(0,0)$ & $3(5,3)$ & \\
$\begin{array}{l}\text { Dewasaakhir } \\
(36-45)\end{array}$ & $5(8,8)$ & $3(5,3)$ & 0,014 \\
& $\begin{array}{l}\text { Lansiaawal } \\
(46-55)\end{array}$ & $4(7,0)$ & $3(5,3)$ & \\
$\begin{array}{l}\text { Lansiaakhir } \\
(56-65)\end{array}$ & 14 & $8(14,0)$ & \\
& $(2, .6)$ & $3(5,3)$ & \\
\hline
\end{tabular}

$X^{-}$: 56; Me: 60; S: 13,65; Nilai Minimal: 24; Nilai Maksimal; 75

\begin{tabular}{lllll}
\hline 2. & Jenis & & & 0,005 \\
& Kelamin & & & \\
& Perempuan & $17(2,8)$ & 18 & \\
& Laki-laki & 19 & $(31,6)$ & \\
& & $(33,3)$ & $3(5,3)$ & \\
\hline 3. & Tingkat & & & \\
& Pendidikan & & & \\
& SD & 12 & 11 & 0,381 \\
& SMP & $(21,1)$ & $(19,3)$ & \\
& SMA & $5(8,8)$ & $2(3,5)$ & \\
& Doploma & $9(15,8)$ & $3(5,3)$ & \\
& Sarjana & $0(0,0)$ & $2(3,5)$ & \\
& & $9(15,8)$ & $4(7,0)$ & \\
\hline 4. & Status & & & 0,050 \\
& Pekerjaan & & & \\
& Bekerja & 25 & 10 & \\
& Tidak bekerja & $(4, .9)$ & $(17,5)$ & \\
& & 10 & 12 & \\
& & $(17,5)$ & $(21,1)$ & \\
\hline
\end{tabular}

Dari tabel 1 dapat diketahui distribusi frekuensi karakteristik data demografi responden yang paling tertinggi adalah dengan kategori usia lansia akhir 56-65 tahun sebanyak 22 responden $(38,6 \%)$, jenis kelamin perempuan sebanyak 35 responden $(61,4 \%)$, tingkat pendidikan SD sebanyak 32 responden $(40,4 \%)$, dan bekerja sebanyak 35 responden $(61,4 \%)$.

Pada tabel 1 juga dijelaskan bahwa berdasarkan analisis uji chi-square dan spearmen rank yang dilakukan, karakteristik responden yang 
mempengaruhi kualitas tidur penderita hipertensi adalah usia $(\mathrm{p}=0,014)$ dan jenis kelamin $(\mathrm{p}=$ 0,005).

\section{Faktor-faktor mempengaruhikualitastidurpenderitahipertensi}

Tabel 2. Distribusifrekuensidanhubunganfaktorfaktorindependendengankualitastidurpenderitahiper tensi

\begin{tabular}{|c|c|c|c|c|}
\hline \multirow[b]{2}{*}{$\begin{array}{c}\text { No } \\
\text { • }\end{array}$} & \multirow[b]{2}{*}{ Karakteristik } & \multicolumn{3}{|c|}{ Kualitastidur } \\
\hline & & $\begin{array}{l}\text { Baik } \\
\text { (f/\%) }\end{array}$ & $\begin{array}{l}\text { Buru } \\
\text { k } \\
(\mathbf{f} / \%)\end{array}$ & $\begin{array}{l}\mathbf{P} \\
\text { valu } \\
\mathbf{e}\end{array}$ \\
\hline 1. & $\begin{array}{l}\text { Derajathipertensi } \\
\text { Derajat } 1 \\
\text { Derajat } 2 \\
\text { Derajat } 3\end{array}$ & $\begin{array}{l}22 \\
(38,6 \\
) \\
8 \\
(14,0 \\
) \\
5 \\
(8,8)\end{array}$ & $\begin{array}{l}10 \\
(17,5) \\
11 \\
(7,3) \\
1 \\
(1,8)\end{array}$ & $\begin{array}{l}0,42 \\
6\end{array}$ \\
\hline 2. & $\begin{array}{l}\text { KebiasaanMeroko } \\
\mathbf{k} \\
\text { Ya } \\
\text { Tidak }\end{array}$ & $\begin{array}{l}10 \\
(17,5 \\
) \\
25 \\
(43,9 \\
) \\
\end{array}$ & $\begin{array}{l}3 \\
(5,3) \\
19 \\
(33,3)\end{array}$ & $\begin{array}{l}0,19 \\
1\end{array}$ \\
\hline 3. & $\begin{array}{l}\text { Konsumsi Kopi } \\
\text { Ya } \\
\text { Tidak }\end{array}$ & $\begin{array}{l}20 \\
(35,1 \\
) \\
15 \\
(26,3 \\
) \\
\end{array}$ & $\begin{array}{l}11 \\
(19,3) \\
11 \\
(19,3)\end{array}$ & $\begin{array}{l}0,59 \\
8\end{array}$ \\
\hline 4. & $\begin{array}{l}\text { Stress Psikososial } \\
\text { Normal } \\
\text { Ringan } \\
\text { Sedang } \\
\text { Parah } \\
\text { Sangatparah }\end{array}$ & $\begin{array}{l}18 \\
(31,6 \\
) \\
4 \\
(7,0) \\
2 \\
(3,5) \\
9 \\
(15,8 \\
) \\
2 \\
(3,5)\end{array}$ & $\begin{array}{l}5 \\
(8,8) \\
0 \\
(0,0) \\
2 \\
(3,5) \\
5 \\
(8.8) \\
10 \\
(4,6)\end{array}$ & $\begin{array}{l}0,00 \\
1\end{array}$ \\
\hline
\end{tabular}

Berdasarkan tabel 2 diatas, dapat dijelaskan bahwa faktor yang mempengaruhi kualitas tidur penderita hipertensi adalah stress psikososial dengan nilai $\mathrm{p}$ value $=0,001$.
Penelitian yang dilakukanoleh Wang, et al (2017), menyatakanbahwadurasitidur yang singkatdangangguantidur yang berhubungandenganhipertensiterjadipadakelompok usiadiatas 60 tahun, haltersebutterjadikarenagangguanpernafasansaattid ur, faktorekstrogen, penurunankebutuhantidur, karenalansialebihbanyakmenghabiskanwaktudirum ahsehinggamemungkinkantidursiang yang lama, dansebgaianbesarlansiamemilikipenyakitpenyerta (11). PenelitianolehGraner (2018), juga menyatakanbahwatidur yang singkatdikaitkandenganrisikohipertensipadawanitad ibandingkandenganpria,

danhaltersebutterjadisepanjanghidupnya (2).

$$
\text { Selain itu, }
$$

penderitahipertensimemilikitingkatkecemasan yang tinggisehinggaterjadigangguanemosidangangguanti dur yang akhirnyaakanmempengaruhikualitastidurnya (9). Kecemasantersebutdapatdiperparaholehusiadanjenis kelamindikarenakanpenurunanhormon estrogen yang

mempengaruhipsikologissehinggaberpengaruhterha dapkualitastidur (9).

Hal

tersebutsesuaidenganpenjelasanAspiani (2014) (1), yang menyatakanbahwa stress psikologisakanmemungkinkanmemunculkankecem asan yang bisamenyebabkangangguanpadafrekuensitidurkaren asaatcemasakanmeningkatkanneropineprin.

Selainitu,

padapenderitahipertensikeadaanstres yang terusmenerusakanmempengaruhikualitastidurnya,

karenapadasaatstrestubuhmenghasilkanhormon

yang disebutkortisol, hormoninidiproduksiolehkelenjar adrenal. Kadar kortisol yang tinggiakanmenyebabkangangguantidurpadaseseoran gkarenamenghambatproduksi melatonin, yaitusuatuhormon yang mengaturritme circadian danberakibatpadakualitastidur yang burukpadapenderitahipertensi. Kualitastidur yang burukpadapenderitahipertensiakanmemperburukpen yakitnyakarenabebankerjajantungmeningkat,

sehinggamenyebabkantekanandarah yang tinggipadapenderitahipertensisaatdilakukanpemerik saantekanandarah (3).

Pengalamanpsikologisstresmemicusistemr esponsstres.

Sistemresponsstresmengaktifkansistemsarafsimpati sdansumbuhipotalamus-hipofisisadrenal (HPA). Hasildariaktivasiinidapatmenundapermulaantidurda nmenyebabkantidurlebih lama, berpotensipadakualitastidur yang burukdanmengganggudurasitidur. Selanjutnya, strespsikososialdapatmempengaruhitidursecaratidak 
langsungmelaluiperilaku tidaksehatsepertipolamakan kurangnyaaktivitasfisik, peningkatanaktivitasmenetap. yang buruk, ataufaktorrisiko lain seperti diabetes, hipertensi, ataugejaladepresi (4).

Strespsikososialmendorongpeningkatanse

mentaratekanandarah. Secaramekanis, mengikutipersepsistresakut,

terjadialiranperubahanpadasistemsaraf,

kardiovaskular, endokrin, danginjal. Jikaresponstresakuttersebuttetapterjadi,

makaakanberdampakmaladaftif. simulasi SNS kronisdarisistemkardiovaskularakanmenyebabkanp eningkatantekanandarah yang terus-menerus, hipertrofivaskular, danpembentukanplak. Efeklainnyatekait stress adalahmakanberlebihan, konsumsialkoholdantidur yang burukmerupakanfisiologislangsungdaristres(6).

\section{KESIMPULAN}

Berdasarkanhasilpenelitian, Faktor-faktor yang mempengaruhikualitastidurpenderitahipertensiadala husia, jeniskelamindan stress psikososial.

Diharapkanhasilpenelitianinidapatdijadika nrekomendasidalampenanganandanpencegahanhipe rtensimelaluikontroldanpenangananstress

pasiendenganintervensi yang sesuai, sehinggakontrol stress dapatmengatasigangguantidurpasien yang hasilakhirnyadapatmenanganihipertensipasien.

Rekomendasiuntukpenelitianselanjutnya, diharapkanpenelitianlebihlanjutdengankarakteristikr esponden yang lebihberagamdantambahan variable lain yang mungkinberpengaruhdenganjumlahsampel yang lebihbanyaksehinggahasilpenelitiandapatdigeneralis asikan.

\section{DAFTAR PUSTAKA}

1. Aspiani,ReniYuli.(2014).BukuAjarAsuhanKe perawatanGerontik. AplikasiNanda, NIC, NOC jilid 2. Jakarta: TIM

2. Grandner, M., Mullington, J. M., Hashmi, S. D., Redeker, N. S., Watson, N. F., \& Morgenthaler, T. I. (2018). Sleep duration and hypertension: Analysis of $>700,000$ adults by age and sex. Journal of Clinical Sleep

Medicine, 14(6), 1031-1039.

https://doi.org/10.5664/jcsm.7176

3. Harfiantoko, M. N., \& Kurnia, E. (2013). Derajat Hipertensi (Menurut WHO)
Mempengaruhi Kualitas Tidur dan Stress Psikososial. Jurnal STIKES, 6(2), 1-12.

4. Johnson, D. A., Lisabeth, L., Lewis, T. T., Sims, M., Hickson, D. M. A., Samdarshi, T., Taylor, H., \& Diez Roux, A. V. (2016). The contribution of psychosocial stressors to sleep among African Americans in the Jackson heart study. Sleep, 39(7), 1411-1419. https://doi.org/10.5665/sleep.5974

5. KEMENKES RI, 2018. Profil Kesehatan Provinsi Jawa Timur Tahun 2017. Dinas Kesehatan Provinsi Jawa Timur. Surabaya

6. Liu, M. Y., Li, N., Li, W. A., \& Khan, H. (2017). Association between psychosocial stress and hypertension: a systematic review and meta-analysis. Neurological Research, 39(6), 573-580. https://doi.org/10.1080/01616412.2017.131790 4

7. Liu, R., Qian, Z., Trevathan, E., Chang, J., Zelicoff, A., Hao, Y., \& Lin, S. (2015). Poor sleep quality associated with high risk of hypertension and elevated bloodpressureinChina:resultsfromalargepopul ation-basedstudy,39(1), 5459.https://doi.org/10.1038/hr.2015.98

8. Martini, Santi., Shofi, Roshifanni., Fanni, Marzela. (2018). Pola Tidur yang Buruk Meningkatkan Resiko Hipertensi. Jurnal MKMI. Vol 14 No. 3, September 2018

9. Sakinah, P. R., Kosasih, C. E., \& Sari, E. A. (2018). Gambaran Kualitas Tidur Pada Penderita Hipertensi Quality of Sleep Among Hypertension Patients. Media Kesehatan Politeknik Kesehatan Makassar, 13(2), 46. https://doi.org/10.32382/medkes.v13i2.663

10. Suwartika, I \& Cahyati, P (2015). Analisis Faktor Yang Berpengaruh Terhadap Kualitas Tidur Pasien Gagal Jantung Di Rsud Kota Tasikmalaya. Jurnal Skolastik Keperawatan Vol. 1, No.1.

11. Wang, D., Zhou, Y., Guo, Y., Zhang, R., Li, W., He, M., Zhang, X., Guo, H., Yuan, J., Wu, T., \& Chen, W. (2017). The effect of sleep duration and sleep quality on hypertension in middle-aged and older Chinese: the DongfengTongji Cohort Study. Sleep Medicine, 40, 7883. https://doi.org/10.1016/j.sleep.2017.09.024

12. World Health Organization, 2015. Data Hipertensi Global, WHO, Asia Tenggara. 